\title{
Spatiotemporal brain activation pattern following acute citalopram challenge is dose dependent and associated with neuroticism: A human phMRI study
}

Andrea Edit Edes $^{\mathrm{a}, \mathrm{b}}$, Shane McKie ${ }^{\mathrm{c}}$, Edina Szabo ${ }^{\mathrm{a}, \mathrm{b}, \mathrm{d}, \mathrm{e}}$, Gyongyi Kokonyei ${ }^{\mathrm{a}, \mathrm{b}, \mathrm{e}}$, Dorottya Pap ${ }^{\mathrm{b}}$ Terezia Zsombok ${ }^{\mathrm{f}}$, Gabor Hullam ${ }^{\mathrm{g}}$, Xenia Gonda ${ }^{\mathrm{b}, \mathrm{h}, \mathrm{i}}$, Lajos R. Kozak ${ }^{\mathrm{j}}$, Martyn McFarquhar ${ }^{\mathrm{k}}$, Ian M. Anderson ${ }^{\mathrm{k}}$, J.F. William Deakin ${ }^{\mathrm{k}}$, Gyorgy Bagdy ${ }^{\mathrm{b}, \mathrm{i}}$, Gabriella Juhasz ${ }^{\mathrm{a}, \mathrm{b}, \mathrm{k}, *}$

${ }^{a}$ SE-NAP2 Genetic Brain Imaging Migraine Research Group, Semmelweis University, Budapest, Hungary

${ }^{\mathrm{b}}$ Department of Pharmacodynamics, Faculty of Pharmacy, Semmelweis University, Budapest, Hungary

${ }^{\mathrm{c}}$ Faculty of Biological, Medical and Human Sciences Platform Sciences, Enabling Technologies \& Infrastructure, Faculty of Biological, Medical and Human Sciences

Research and Innovation, The University of Manchester and Manchester Academic Health Sciences Centre, Manchester, United Kingdom

${ }^{\mathrm{d}}$ Doctoral School of Psychology, ELTE Eotvos Loránd University, Budapest, Hungary

e Institute of Psychology, ELTE Eotvos Loránd University, Budapest, Hungary

${ }^{\mathrm{f}}$ Department of Neurology, Faculty of Medicine, Semmelweis University, Budapest, Hungary

${ }^{\mathrm{g}}$ Department of Measurement and Information Systems, Budapest University of Technology and Economics, Faculty of Electrical Engineering and Informatics, Budapest,

Hungary

${ }^{\mathrm{h}}$ Department of Psychiatry and Psychotherapy, Semmelweis University, Budapest, Hungary

${ }^{i}$ MTA-SE Neuropsychopharmacology and Neurochemistry Research Group, Hungarian Academy of Sciences, Semmelweis University, Budapest, Hungary

${ }^{\mathrm{j}}$ MR Research Center, Semmelweis University, Budapest, Hungary

${ }^{\mathrm{k}}$ Neuroscience and Psychiatry Unit, Division of Neuroscience and Experimental Psychology, School of Biological Sciences, Faculty of Biological, Medical and Human

Sciences, The University of Manchester and Manchester Academic Health Sciences Centre, Manchester, United Kingdom

\section{H I G H L I G H T S}

- Intravenous citalopram acutely elicited brain activation in several regions involved in serotonergic neurotransmission.

- Acute citalopram challenge produced a chemically-induced brain state similar to increased arousal.

- Significant dose-dependent activation was demonstrated in the middle cingulate gyrus, a region with neuroticism-related functions.

- The neuroticism personality trait was associated with the individual responses to citalopram challenge.

- These results may further support the modulating effects of serotonin on processing environmental stressors.

\section{A R T I C L E I N F O}

\section{Keywords:}

Pharmacological magnetic resonance imaging SSRI

Time-series analysis

Middle cingulate gyrus

Personality

Endophenotype

\begin{abstract}
A B S T R A C T
Background: The initial effects of selective serotonin reuptake inhibitors (SSRIs) in the human living brain are poorly understood. We carried out a 3T resting state fMRI study with pharmacological challenge to determine the brain activation changes over time following different dosages of citalopram.

Methods: During the study, $7.5 \mathrm{mg}$ i.v. citalopram was administered to 32 healthy subjects. In addition, $11.25 \mathrm{mg}$ citalopram was administered to a subset of 9 subjects to investigate the dose-response. Associations with neuroticism (assessed by the NEO PI-R) of the emerging brain activation to citalopram was also investigated. Results: Citalopram challenge evoked significant activation in brain regions that are part of the default mode network, the visual network and the sensorimotor network, extending to the thalamus, and midbrain. Most effects appeared to be dose-dependent and this was statistically significant in the middle cingulate gyrus. Individual citalopram-induced brain responses were positively correlated with neuroticism scores and its subscales in specific brain areas; anxiety subscale scores in thalamus and midbrain and self-consciousness scores in middle cingulate gyrus. There were no sex differences.

Limitations: We investigated only healthy subjects and we used a relatively low sample size in the $11.25 \mathrm{mg}$
\end{abstract}

\footnotetext{
* Corresponding author. Department of Pharmacodynamics, Semmelweis University, Budapest, Hungary.

E-mail address: juhasz.gabriella@pharma.semmelweis-univ.hu (G. Juhasz).
} 
citalopram analysis.

Discussion: Our results suggest that SSRIs acutely induce an increased arousal-like state of distributed cortical and subcortical systems that is mediated by enhanced serotonin neurotransmission according to levels of neuroticism and underpins trait sensitivity to environmental stimuli and stressors. Studies in depression are needed to determine how therapeutic effects eventually emerge.

\section{Introduction}

Pharmacological magnetic resonance imaging (phMRI) has become widely used to follow the effects of drugs in modulating neural information processing (Anderson et al., 2008; Khalili-Mahani et al., 2017). Experimental administration of SSRIs has been used to acutely increase synaptic serotonin content and to observe modulatory effects on brain responses evoked by cognitive and emotion processing tasks in phMRI studies (Anderson et al., 2008). For example, following the first study by Del Ben et al., (2005) (Del-Ben et al., 2005), several studies have reported acute reduction of amygdala activation to viewing fearful faces in healthy volunteers after a single dose of selective serotonin reuptake inhibitors (SSRI). In depressed patients, suppression of amygdala responses to fearful faces occurs early in treatement and predicts subsequent therapeutic benefit (Anderson et al., 2011; Godlewska et al., 2012, 2016; Harmer et al., 2006; Klomp et al., 2013; Murphy et al., 2009). A number of studies have reported modulatory phMRI effects not only on emotion processing (Anderson et al., 2007, 2011; Harmer et al., 2003; Pringle and Harmer, 2015), but also on reward and punishment sensitivity (Macoveanu, 2014), attention, memory and response inhibition (Anderson et al., 2008). More recently a number of studies have described modulation of connectivity in resting-state networks by SSRIs and other drugs in humans (Klaassens et al., 2015, 2017, 2018) and rodents (Schaefer et al., 2014; Schwarz et al., 2009).

SSRI-induced modulation of BOLD responses to cognitive tasks could result from direct effects of increased synaptic serotonin content acting on serotonin receptors to alter postsynaptic neuronal activity in information processing systems. This has led some studies to use challenge phMRI to follow the direct effects of SSRI-induced enhancement of extracellular levels of serotonin on regional brain BOLD signals. SSRI challenge phMRI requires the use of acute intravenous administration while recording the ensuing BOLD signal changes given that they are relative, and not absolute, measures. McKie and colleagues reported increasing BOLD signal following i.v. citalopram in the caudate, amygdala, hippocampus, striatum and thalamus in 12 healthy male volunteers compared to i.v. saline (McKie et al., 2005). Similar results have been observed in rodents (Schwarz et al., 2007; Sekar et al., 2011). Although this method has the potential to quantify the dynamism of serotonergic neurotransmission in disorders such as depression, this has not yet been realised. In this study we determine the replicability of the McKie paradigm, characterise the time course and dose responsiveness, and determine whether regional responsiveness relates to the personality trait of neuroticism.

The serotonin transporter, which is the main target of SSRIs, is a key determinant of brain serotonergic function controlling the duration and extent of serotonergic neurotransmission (Hariri and Holmes, 2006). In early life central serotonergic tone modulates development of the sensory system and the corticolimbic circuits (Booij et al., 2015; Gaspar et al., 2003) that may contribute to behavioural traits such as neuroticism which acts as a vulnerability factor for several neuropsychiatric disorders (Gaspar et al., 2003; Hariri and Holmes, 2006; Lesch et al., 1996). Neuroticism is an endophenotype and major risk factor for disorders treated by SSRIs such as anxiety, depression and chronic pain (Kendler et al., Arch Gen Psychiatry. 2006; Kendler et al., Psychological Medicine, 2007; Ligthart et al., Twin Res Hum Gen, 2012). Previous human studies suggested that neuroticism and alterations in emotion processing were associated with genetically less active serotonin transporter gene variants (5-HTTLPR) (Hariri and Holmes, 2006; Lesch et al., 1996; Munafo et al., 2009), although some studies (Middeldorp et al., 2007; Terracciano et al., 2009; Willis-Owen et al., 2005) and a large whole genome association study (GWAS) have failed to support this hypothesis (Smith et al., 2016). One explanation for the inconsistent genetic results is that the less active serotonin transporter, putatively associated with increased synaptic serotonin content, might amplify processing of both positive and stressful environmental stimuli as reported in gene-environment interaction studies (Belsky et al., 2009) and in a human experimental SSRI study (Fox et al., 2011). Similarly, it has been hypothesised that SSRIs acutely facilitate positive sensory information processing that may be related to their therapeutic effect (Browning et al., 2007; Castren, 2005, 2013; Harmer et al., 2003; Harmer and Cowen, 2013). Furthermore, according to the neuroplasticity theory, the therapeutic effect of long-term SSRI treatment is mediated by changes in synaptic plasticity in interaction with environmental factors (Kraus et al., 2017; Umemori et al., 2018).

In the present study we used acute intravenous (i.v.) citalopram challenge to investigate the regional pattern and sequence of brain activation to increases in synaptic serotonin content. Citalopram is a highly selective SSRI and the only one available in i.v. form. Previous studies demonstrated that i.v. administration of citalopram is well tolerated, and even a low dose of citalopram leads to a neuroendocrine response inducing increased plasma prolactin and cortisol levels (Attenburrow et al., 2001; Lotrich et al., 2005). Based on the previous results we predicted that using a time-series analysis of BOLD signal changes from baseline during and after acute i.v. citalopram administration (McKie et al., 2005), a dose-dependent increased BOLD signal would occur in several brain regions involved in sensory information and in turn emotional information processing.

As previous phMRI studies repeatedly showed that SSRI drugs have influence on amygdala function while performing different tasks (Godlewska et al., 2012; Harmer et al., 2006; Murphy et al., 2009) and in rest (McKie et al., 2005), we made an exploratory analysis of the BOLD response of amygdala to acute citalopram challenge. In addition we used a novel data-driven network analysis to identify which regional BOLD responses relate to neuroticism and its component traits.

\section{Material and methods}

The Scientific and Research Ethics Committee of the Medical Research Council, Budapest, Hungary approved the study. Participants gave written informed consent after receiving oral and written information. The work was conducted in accordance with the Declaration of Helsinki.

\subsection{Participants}

Thirty-two healthy right-handed volunteers (mean age $\pm \mathrm{SD}=25.8 \pm 4.16$ years; 19 female) between 18 and 50 years of age and recruited through advertisement participated in the study. Participants were screened for eligibility criteria and underwent a medical examination (including routine physical, psychiatric and neurological examination, routine blood tests, and ECG carried out by specialist medical researchers) to determine that they met inclusion and exclusion criteria. Exclusion criteria were current or past serious medical, neurological and psychiatric disorders and long-term medication use. Volunteers with any history of psychotropic medication use and 
excessive consumption of alcohol were excluded. All included participants were healthy and did not take any medication on a regular basis (oral contraceptives were permitted). Participants were asked to refrain from any medication for at least 2 days, from alcohol for at least $24 \mathrm{~h}$ and from caffeine for at least $4 \mathrm{~h}$ before the scanning sessions.

\subsection{Self-report measure of personality dimensions}

Thirty-one participants (age $=26.0 \pm 4.24$ years; 18 women) completed the Revised NEO Personality Inventory (NEO PI-R) (Costa and McCrae, 1992) to assess neuroticism during the screening procedure.

\subsection{Experimental design}

All participants were invited for two separate scanning sessions during which phMRI scans were acquired. Anatomical dataset acquisition was performed on the first occasion. During two 30-minute phMRI sessions all participants received normal saline or $7.5 \mathrm{mg}$ citalopram infused over $7.5 \mathrm{~min}$ in a randomized, balanced-order, doubleblind design. Scanning sessions were separated by at least two weeks. $7.5 \mathrm{mg}$ dose intravenous citalopram was chosen according to a previous study (McKie et al., 2005). Nine of 32 participants (age $=25.9 \pm 5.21$ years; 6 women) volunteered in an additional experiment and repeated the drug challenge with $11.25 \mathrm{mg}$ citalopram.

Participants were cannulated outside the scanner at least $45 \mathrm{~min}$ before they underwent the drug challenge. The baseline saline infusion lasted $10 \mathrm{~min}$ at the beginning of the scanning session followed by citalopram or saline infusion for $7.5 \mathrm{~min}$. During the experiment, participants rested viewing a blank screen. Every 5 min participants rated their subjective experiences with a yes/no button press for the following statements: anxious, nauseous, drowsy, lightheaded, restless and uncomfortable. Blood pressure and pulse rate were recorded twice: $2 \mathrm{~h}$ before and $1 \mathrm{~h}$ after the phMRI sessions.

\subsection{Data acquisition}

Functional MRI images were acquired at a 3T MRI scanner (Achieva 3T, Philips Medical System) using an eight-channel SENSE coil and BOLD-sensitive T2*-weighted echo-planar (EPI) pulse sequence $(\mathrm{TR}=2.500 \mathrm{~ms}$, TE $=30 \mathrm{~ms}$, FOV: $240 \times 240 \mathrm{~mm} 2)$ with $3 \mathrm{~mm} \times 3 \mathrm{~mm}$ in-plane resolution and $3 \mathrm{~mm}$ slice thickness. The number of slices was 46 and the EPI sequence length was $1.800 \mathrm{~s}$. A series of anatomical image acquisitions were made using a T1-weighted 3D TFE sequence with $1 \times 1 \times 1 \mathrm{~mm}$ resolution.

\section{5. fMRI data analysis}

Imaging data were analysed with Statistical Parametric Mapping (SPM 12, Friston, The Welcome Department of Cognitive Neurology, London, UK) using the phMRI analysis method as described by McKie et al. (2005). SPM unified segmentation algorithm with default settings was used for normalisation of the data (Wellcome Department of Imaging Neuroscience, Institute of Neurology, London, UK; http://www.fil. ion.ucl.ac.uk/spm12/). Images were realigned using the first scan as reference. These realigned images were then segmented based on individual T1 images and then spatially normalised to MNI space. The normalised images were smoothened with an $8 \mathrm{~mm}$ Gaussian kernel. Additional parameters were made for correction of movement using the Artifact Detection Tools (ART; http://www.nitrc.org/projects/artifact_ detect/), which were then applied to the first level analysis as a regressor.

First level analysis was performed by splitting the phMRI scan into 30 consecutive 1-minute time bins (T01 to 30 ; averaging over 1-minute reduces variance while still providing detailed time information of changes caused by the drug). The images were then normalised by subtraction of T01 from each subsequent time bin to produce first-level contrast images. The effects of signal drift of the scanner were controlled by modelling the drift in the saline condition across participants. Then an individually scaled version of the saline drift model was subtracted from each participant's first level contrasts. After this step, the saline time bin images were subtracted from the corresponding citalopram time bin images. We used the baseline time bin (T10) and 20 postinfusion time bins (T11-T30) for the second-level analysis, as in our previous studies (Downey et al., 2016; Symonds et al., 2012). For further details related to drift correction and baseline selection methods see Supplementary Materials (Supplementary Figs. 1 and 2 and Supplementary Tables 1 and 2).

The 21 images were entered into a whole-brain second level repeated measure ANOVA using the flexible factorial option in SPM to investigate time by treatment interaction with time as a repeated measure factor and F-tests for statistical significance (McFarquhar, 2019). To investigate the dose-effect of citalopram, the time bins from $7.5 \mathrm{mg}$ citalopram scans were subtracted from those of $11.25 \mathrm{mg}$ citalopram in participants receiving both doses, then these time bins were also entered into a second level, flexible factorial analysis. To determine sex differences in citalopram elicited brain activations, sex as a grouping factor was entered into the second level repeated measure ANOVA models using the flexible factorial option in SPM, as described above. Results of whole-brain analysis are reported with cluster level Family Wise Error corrected threshold of $\mathrm{p}(\mathrm{FWE})<0.05$ based on $\mathrm{p}<0.001$ uncorrected primary threshold $(\mathrm{k} \geq 10)$.

We used a hypothesis-testing ROI analysis to investigate citalopram effects in the amygdala in view of its role in short- and long-term SSRI treatment response (Godlewska et al., 2012; Harmer et al., 2006; Murphy et al., 2009). The amygdala ROI was defined according to Anatomical Automatic Labeling atlas (Tzourio-Mazoyer et al., 2002), involving both the left and the right amygdala. Results of ROI analysis are reported with peak level secondary threshold of p(FWE) $<0.05$ at $\mathrm{p}<0.001$ uncorrected primary threshold $(\mathrm{k} \geq 5)$.

\subsection{Statistical analysis of neuroticism and BOLD responses}

Spearman's correlation coefficients were used to determine the relationship between activation changes to $7.5 \mathrm{mg}$ citalopram and neuroticism and its subscales (anxiety, angry-hostility, self-consciousness, impulsiveness, vulnerability and depression). An overall under the curve (AUC) BOLD response to citalopram was calculated for each region in each individual and entered into the correlation matrix. The AUC was the area of raw signal change values for each individual from the final model of $7.5 \mathrm{mg}$ citalopram minus saline analysis at the peak coordinates within the significant clusters. Peak coordinates were determined from the two primary analyses and from the ROI analysis of amygdala. Namely, we used: a.) peak coordinates within the significant clusters of $7.5 \mathrm{mg}$ citalopram minus saline analysis; b.) peak coordinates within the significant clusters of $11.25 \mathrm{mg}$ citalopram minus analysis; and c.) amygdala ROI peak coordinates from the $11.25 \mathrm{mg}$ citalopram minus saline analysis. For further details see Supplementary Materials. Nominal significance was accepted at $\mathrm{p}=0.05$ level. Bonferroni corrected $\mathrm{p}$ values for multiple testing were calculated but considered too stringent because of interdependences between the reported brain regions and also between the neuroticism total and subscale scores. We therefore applied a graphical LASSO (least absolute shrinkage and selection operator) based method with adaptive weights ('Adalasso') in order to identify an 'optimal set' of relationships (LASSO coefficients) between investigated variables using the 'bootnet' $R$ package (Epskamp et al., 2017). The Robustmenss (RB) of each coefficient is the number (\%) of positive occurrences in 100 different models. For further details related to LASSO method see Supplementary Materials. 


\section{Results}

\subsection{Behavioural and physiological data}

A Wilcoxon signed-rank test showed that the number of 'yes' answers to each subjective self-rating did not differ significantly between $7.5 \mathrm{mg}$ citalopram and saline sessions in $\mathrm{n}=32$ participants or between $11.25 \mathrm{mg}$ and saline sessions in $\mathrm{n}=9$ participants (Table 1 ). Neither subjective answers showed any sex differences.

NEO-PI-R neuroticism scores (mean $=81.7 \pm 25.34$ ) showed no sex differences in our participants $(t=1.684, p=0.103)$.

There was no effect of either dose of citalopram on heart rate (beats per minute) or blood pressure (mmHg). For $7.5 \mathrm{mg}$ citalopram vs. saline: heart rate mean difference $=2.9 \pm 10.85, \mathrm{t}=1.516$, $\mathrm{p}=0.140$; systolic blood pressure mean difference $=3.9 \pm 14.77$, $\mathrm{t}=1.449, \mathrm{p}=0.158$; and diastolic blood pressure mean difference $=1.6 \pm 12.83, \mathrm{t}=0.716, \mathrm{p}=0.479$ ). For $11.25 \mathrm{mg}$ citalopram vs. saline sessions: heart rate mean difference $=-1.1 \pm 7.18$, $\mathrm{t}=-0.464, \quad \mathrm{p}=0.655 ;$ systolic blood pressure mean difference $=-2.8 \pm 12.88, \mathrm{t}=-0.647, \mathrm{p}=0.536$; diastolic blood pressure mean difference $=-2.0 \pm 12.81, \mathrm{t}=-0.469, \mathrm{p}=0.652$ ).

\section{2. $7.5 \mathrm{mg}$ citalopram minus saline analysis}

Analysis of $7.5 \mathrm{mg}$ citalopram data led to time-dependent effects on citalopram -saline diffrerences in several brain areas within three clusters; the most extensive activations occurred in the lingual gyrus, posterior cingulate cortex, the precuneus and the parahippocampal gyrus. In addition, significant activation appeared in two clusters including the right postcentral gyrus, left middle temporal and middle occipital areas (Table 2 and Fig. 1). There was no significant difference between males and females in the effect of $7.5 \mathrm{mg}$ citalopram on wholebrain BOLD signal changes.

We found no significant difference in BOLD signal responses to $7.5 \mathrm{mg}$ citalopram between the $\mathrm{n}=9$ participants who later received the higher dose of citalopram, and the other $n=23$ participants.

\section{3. $11.25 \mathrm{mg}$ citalopram minus saline analysis}

Analysis of $11.25 \mathrm{mg}$ citalopram minus saline BOLD data revealed widespread activation in cortical and subcortical structures including clusters extending to the middle cingulate cortex (MCG), inferior frontal gyrus, thalamus and midbrain (Table 3, Fig. 2). The caudate, which showed significantly increased activation only at an uncorrected $\mathrm{p}<0.001$ threshold in $7.5 \mathrm{mg}$ citalopram minus saline analysis (MNI coordinates $=9,11,2 ; \mathrm{F}=2.72$ ), was fully FWE-corrected significant in the $11.25 \mathrm{mg}$ analysis (Table 2).

\section{4. $11.25 \mathrm{mg}$ citalopram minus $7.5 \mathrm{mg}$ citalopram analysis}

The dose-effect analysis showed that significant time-dependent BOLD responses to $11.25 \mathrm{mg}$ citalopram remained after subtraction of responses to $7.5 \mathrm{mg}$ in a single cluster extending to the MCG ( size $=103$ voxels, MNI coordinates $=24,-16,35$, Peak $F=3.84$ ). Fig. 3 shows activation changes of the MCG in $7.5 \mathrm{mg}$ citalopram minus saline and $11.25 \mathrm{mg}$ citalopram minus saline analysis over time.
Table 2

Areas with significant time $\times$ treatment interaction from $7.5 \mathrm{mg}$ citalopram minus saline analysis at $\mathrm{p}(\mathrm{FWE})<0.05$ secondary threshold.

\begin{tabular}{|c|c|c|c|c|c|c|}
\hline \multirow[t]{2}{*}{ Cluster size } & \multirow[t]{2}{*}{ Region } & \multirow[t]{2}{*}{ Side } & \multirow{2}{*}{$\begin{array}{l}\text { Peak F- } \\
\text { value }\end{array}$} & \multicolumn{3}{|c|}{ Peak MNI Coordinates } \\
\hline & & & & $\mathrm{x}$ & $\mathrm{y}$ & $\mathrm{z}$ \\
\hline \multirow[t]{16}{*}{1205} & Lingual Gyrus & - & 4.46 & 0 & -67 & 5 \\
\hline & Lingual Gyrus & $\mathrm{R}$ & 3.56 & 15 & -61 & 5 \\
\hline & Lingual Gyrus & $\mathrm{L}$ & 3.53 & -15 & -73 & 23 \\
\hline & Posterior Cingulate & $\mathrm{L}$ & 3.40 & -9 & -55 & 8 \\
\hline & $\begin{array}{l}\text { Middle Temporal } \\
\text { Gyrus }\end{array}$ & $\mathrm{R}$ & 3.35 & 39 & -64 & 20 \\
\hline & $\begin{array}{l}\text { Parahippocampal } \\
\text { Gyrus }\end{array}$ & $\mathrm{R}$ & 3.14 & 15 & -46 & 2 \\
\hline & Precuneus & $\mathrm{R}$ & 3.10 & 9 & -73 & 35 \\
\hline & Precuneus & - & 3.07 & 0 & -70 & 41 \\
\hline & Lingual Gyrus & $\mathrm{L}$ & 3.06 & -18 & -64 & 5 \\
\hline & Lingual Gyrus & $\mathrm{R}$ & 3.02 & 21 & -67 & 20 \\
\hline & Posterior Cingulate & $\mathrm{R}$ & 2.96 & 24 & -64 & 17 \\
\hline & Cerebellum & $\mathrm{R}$ & 2.90 & 18 & -61 & -28 \\
\hline & $\begin{array}{l}\text { Parahippocampal } \\
\text { Gyrus }\end{array}$ & $\mathrm{R}$ & 2.87 & 30 & -46 & -10 \\
\hline & $\begin{array}{l}\text { Parahippocampal } \\
\text { Gyrus }\end{array}$ & $\mathrm{R}$ & 2.85 & 24 & -49 & -1 \\
\hline & Precuneus & $\mathrm{R}$ & 2.81 & 24 & -79 & 35 \\
\hline & Fusiform Gyrus & $\mathrm{R}$ & 2.60 & 36 & -46 & -19 \\
\hline \multirow[t]{2}{*}{175} & Postcentral Gyrus & $\mathrm{R}$ & 3.97 & 36 & -34 & 53 \\
\hline & Postcentral Gyrus & $\mathrm{R}$ & 2.91 & 33 & -43 & 62 \\
\hline \multirow[t]{6}{*}{177} & $\begin{array}{l}\text { Middle Temporal } \\
\text { Gyrus }\end{array}$ & $\mathrm{L}$ & 3.72 & -48 & -64 & 20 \\
\hline & $\begin{array}{l}\text { Middle Temporal } \\
\text { Gyrus }\end{array}$ & $\mathrm{L}$ & 3.63 & -45 & -70 & 23 \\
\hline & $\begin{array}{l}\text { Middle Occipital } \\
\text { Gyrus }\end{array}$ & $\mathrm{L}$ & 3.02 & -39 & -79 & 5 \\
\hline & $\begin{array}{l}\text { Middle Temporal } \\
\text { Gyrus }\end{array}$ & $\mathrm{L}$ & 2.97 & -54 & -52 & 8 \\
\hline & $\begin{array}{l}\text { Middle Occipital } \\
\text { Gyrus }\end{array}$ & $\mathrm{L}$ & 2.75 & -48 & -70 & 8 \\
\hline & $\begin{array}{l}\text { Middle Temporal } \\
\text { Gyrus }\end{array}$ & $\mathrm{L}$ & 2.41 & -48 & -55 & 2 \\
\hline
\end{tabular}

$\mathrm{R}=$ right; $\mathrm{L}=$ left $\mathrm{MNI}=$ Montreal Neurological Institute.

An exploratory analysis of the results with a more lenient threshold of $\mathrm{p}<0.05$ with $\mathrm{p}$ (FWE) $<0.05$ revealed that activation differences between the two doses involve extensive brain regions including the caudate, thalamus and middle frontal gyrus (Supplementary Table 3), suggesting that the brain activation pattern is dose-dependent during citalopram challenge.

\subsection{Secondary analyses}

\subsubsection{ROI analysis}

No significant effect of $7.5 \mathrm{mg}$ citalopram was found in the a priori bilateral amygdala ROI but $11.25 \mathrm{mg}$ evoked significant BOLD signal changes bilaterally compared to saline (right: MNI coordinates $=30$, $5,-19, \mathrm{~F}=4.13,9$ voxels; left: $24,-4,-13, \mathrm{~F}=3.59,11$ voxels). Direct comparison of the larger and smaller dose of citalopram showed no significant effect.

Table 1

The results of Wilcoxon signed-rank test of 'yes' answers to questions about subjective states between $7.5 \mathrm{mg}$ citalopram and saline sessions and between $11.25 \mathrm{mg}$ citalopram and saline sessions.

\begin{tabular}{|c|c|c|c|c|c|c|c|c|c|c|c|c|}
\hline & \multicolumn{2}{|l|}{ Anxious } & \multicolumn{2}{|l|}{ Drowsy } & \multicolumn{2}{|c|}{ Lightheaded } & \multicolumn{2}{|c|}{ Nauseous } & \multicolumn{2}{|l|}{ Restless } & \multicolumn{2}{|c|}{ Uncomfortable } \\
\hline & $\mathrm{Z}$ & $\mathrm{p}$ & $\mathrm{Z}$ & $\mathrm{p}$ & $\mathrm{Z}$ & $\mathrm{p}$ & $\mathrm{Z}$ & $\mathrm{p}$ & $\mathrm{Z}$ & $\mathrm{p}$ & $\mathrm{Z}$ & $\mathrm{p}$ \\
\hline $7.5 \mathrm{mg}$ & -1.069 & 0.285 & -1.212 & 0.226 & -1.826 & 0.068 & -1.633 & 0.102 & -0.197 & 0.844 & -0.104 & 0.917 \\
\hline $11.25 \mathrm{mg}$ & 0.000 & 1.000 & -1.490 & 0.136 & -1.000 & 0.317 & -1.342 & 0.180 & -1.732 & 0.083 & 0.000 & 1.000 \\
\hline
\end{tabular}




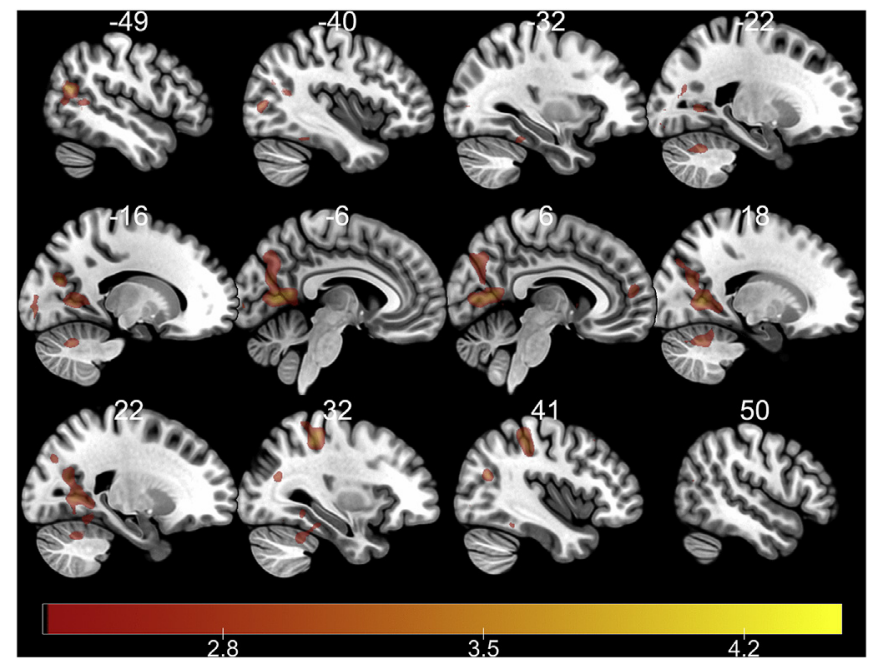

Fig. 1. $7.5 \mathrm{mg}$ citalopram minus saline significant time $\times$ treatment interaction at $\mathrm{p}<0.001$ uncorrected threshold in saggital view.

Table 3

Areas with significant time $\times$ treatment interaction from $11.25 \mathrm{mg}$ citalopram minus saline analysis at $\mathrm{p}(\mathrm{FWE})<0.05$ secondary threshold.

\begin{tabular}{|c|c|c|c|c|c|c|}
\hline \multirow[t]{2}{*}{ Cluster size } & \multirow[t]{2}{*}{ Region } & \multirow[t]{2}{*}{ Side } & \multirow{2}{*}{$\begin{array}{l}\text { Peak f- } \\
\text { value }\end{array}$} & \multicolumn{3}{|c|}{ Peak MNI coordinates } \\
\hline & & & & $\mathrm{x}$ & $\mathrm{y}$ & $\mathrm{z}$ \\
\hline \multirow[t]{2}{*}{59} & $\begin{array}{l}\text { Middle Cingulate } \\
\text { Gyrus }\end{array}$ & $\mathrm{R}$ & 4.88 & 15 & -10 & 35 \\
\hline & $\begin{array}{l}\text { Middle Cingulate } \\
\text { Gyrus }\end{array}$ & $\mathrm{R}$ & 4.76 & 12 & -7 & 38 \\
\hline \multirow[t]{4}{*}{101} & Fusiform Gyrus & $\mathrm{R}$ & 4.86 & 45 & -49 & -22 \\
\hline & Fusiform Gyrus & $\mathrm{R}$ & 4.77 & 39 & -55 & -19 \\
\hline & Fusiform Gyrus & $\mathrm{R}$ & 3.44 & 33 & -43 & -19 \\
\hline & Cerebellum & $\mathrm{R}$ & 3.19 & 27 & -58 & -16 \\
\hline \multirow[t]{3}{*}{327} & Fusiform Gyrus & $\mathrm{L}$ & 4.79 & -39 & -61 & -16 \\
\hline & Cerebellum & $\mathrm{L}$ & 4.56 & -45 & -52 & -7 \\
\hline & Supramarginal Gyrus & $\mathrm{L}$ & 4.56 & -39 & -52 & 32 \\
\hline \multirow[t]{4}{*}{104} & $\begin{array}{l}\text { Parahippocampal } \\
\text { gyrus }\end{array}$ & $\mathrm{R}$ & 4.31 & 30 & 5 & -16 \\
\hline & $\begin{array}{l}\text { Superior Temporal } \\
\text { Gyrus }\end{array}$ & $\mathrm{R}$ & 3.95 & 39 & 20 & -22 \\
\hline & $\begin{array}{l}\text { Superior Temporal } \\
\text { Gyrus }\end{array}$ & $\mathrm{R}$ & 3.84 & 36 & 11 & -31 \\
\hline & $\begin{array}{l}\text { Superior Temporal } \\
\text { Gyrus }\end{array}$ & $\mathrm{R}$ & 3.78 & 33 & 8 & -34 \\
\hline \multirow[t]{7}{*}{119} & Extra-nuclear & $\mathrm{L}$ & 4.29 & -9 & -4 & 2 \\
\hline & Caudate & $\mathrm{L}$ & 4.19 & -15 & 20 & -4 \\
\hline & Caudate & $\mathrm{L}$ & 4.18 & -6 & 5 & -4 \\
\hline & Thalamus & $\mathrm{R}$ & 3.89 & 6 & 8 & 2 \\
\hline & Caudate & $\mathrm{R}$ & 3.85 & -6 & 11 & 8 \\
\hline & Caudate & $\mathrm{L}$ & 3.60 & 9 & -1 & 11 \\
\hline & Caudate & $\mathrm{R}$ & 3.21 & 9 & -13 & 17 \\
\hline \multirow[t]{7}{*}{75} & Extra-nuclear & $\mathrm{L}$ & 4.26 & -21 & -16 & -7 \\
\hline & Extra-nuclear & $\mathrm{L}$ & 4.02 & -24 & -19 & 2 \\
\hline & Thalamus & $\mathrm{L}$ & 3.98 & -18 & -25 & 5 \\
\hline & Midbrain & $\mathrm{L}$ & 3.88 & -9 & -25 & -1 \\
\hline & Thalamus & $\mathrm{L}$ & 3.71 & -18 & -19 & -4 \\
\hline & Midbrain & $\mathrm{L}$ & 3.55 & -12 & -31 & -4 \\
\hline & Extra-nuclear & $\mathrm{L}$ & 3.14 & -30 & -25 & 2 \\
\hline \multirow[t]{3}{*}{121} & $\begin{array}{l}\text { Middle Temporal } \\
\text { Gyrus }\end{array}$ & $\mathrm{R}$ & 4.19 & 54 & -52 & 8 \\
\hline & $\begin{array}{l}\text { Middle Temporal } \\
\text { Gyrus }\end{array}$ & $\mathrm{R}$ & 4.01 & 48 & -61 & 8 \\
\hline & $\begin{array}{l}\text { Superior Temporal } \\
\text { Gyrus }\end{array}$ & $\mathrm{R}$ & 3.92 & 57 & -55 & 23 \\
\hline \multirow[t]{5}{*}{74} & Inferior Frontal Gyrus & $\mathrm{R}$ & 3.92 & 45 & 23 & 17 \\
\hline & Inferior Frontal Gyrus & $\mathrm{R}$ & 3.90 & 39 & 17 & 38 \\
\hline & Middle Frontal Gyrus & $\mathrm{R}$ & 3.80 & 39 & 11 & 35 \\
\hline & Precentral gyrus & $\mathrm{R}$ & 3.72 & 39 & 20 & 26 \\
\hline & Middle Frontal Gyrus & $\mathrm{R}$ & 3.29 & 51 & 17 & 17 \\
\hline
\end{tabular}

$\mathrm{R}=$ right; $\mathrm{L}=$ left; $\mathrm{MNI}=$ Montreal Neurological Institute.

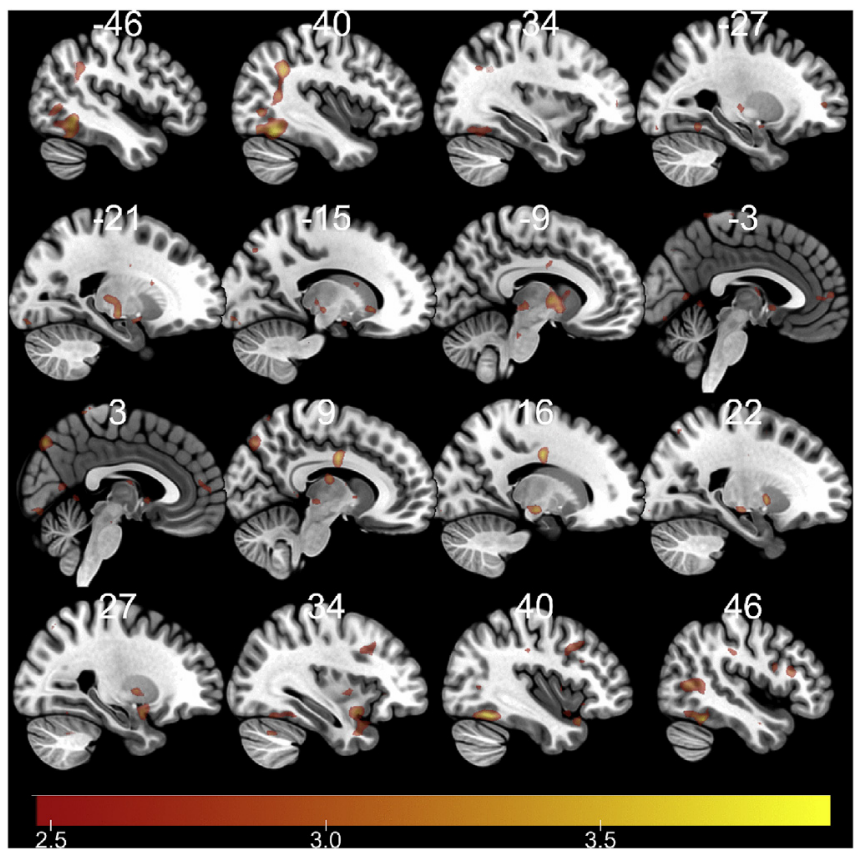

Fig. 2. $11.25 \mathrm{mg}$ citalopram minus saline significant time $\times$ treatment interaction at $\mathrm{p}<0.001$ uncorrected threshold in sagittal view.

\subsubsection{Time-series analysis}

Visual inspection showed that the statistically significant time-dependent differences between $7.5 \mathrm{mg}$ citalopram and saline is due to a gradually increasing citalopram-saline difference. Supplementary Fig. 3 shows the BOLD signal time course in the most significant peaks of the 3 clusters, i.e. in the lingual gyrus, in the postcentral gyrus and in the middle temporal gyrus (MTG). To determine and visualise the order of the spatiotemporal changes during the $7.5 \mathrm{mg}$ citalopram challenge paired t-tests were applied to compare successive time bins to the baseline using the flexible factorial repeated measure ANOVA model. The first significant activation change occurred in the occipital cortex $7 \mathrm{~min}$ after citalopram infusion started $(12,-76,2 ; \mathrm{T}=4.56,1919$ voxels). The activation spread in a posterior-anterior direction, significant frontal activation first emerging in the medial frontal gyrus $(-12,59,26 ; \mathrm{T}=4.55,165$ voxels $)$ in the 11 th minute as the occipital activation intensified and spread $(-12,-97,-4 ; \mathrm{T}=5.61,4340$ voxels). The Supplementary video shows the statistically significant BOLD signal changes (t-tests) emerging over 1 min time bins from the onset of the infusion at $\mathrm{p}<0.001$ primary height threshold without correction.

\subsubsection{Neuroticism-associated changes in brain activity}

3.5.3.1. Correlation between neuroticism and citalopram-evoked brain activation. Neuroticism scores positively correlated with AUC BOLD responses in thalamus $(r=0.49, \mathrm{p}=0.005)$ and midbrain $(\mathrm{r}=0.41$, $\mathrm{p}=0.021)$. The strongest and most significant correlations were between the thalamus activation and the anxiety subscale of neuroticism $(r=0.63, p=0.0002)$ and the right MTG and selfconsciousness $(r=0.48, \quad p=0.006)$. For detailed results, see Supplementary Table 4 and Supplementary Fig. 4. Using Bonferroni correction (7 neuroticism scores, 14 brain regions, threshold $\mathrm{p}<0.0005$ ) only the correlation between the thalamus AUC and the anxiety subscale remained significant. However, because of interdependencies between the investigated variables we used LASSO method to model our data.

3.5.3.2. LASSO regression analysis of neuroticism scores and citalopramevoked brain activation. We modelled the 6 subscales of neuroticism with sex, age and the BOLD response (AUC) to increased serotonin of 


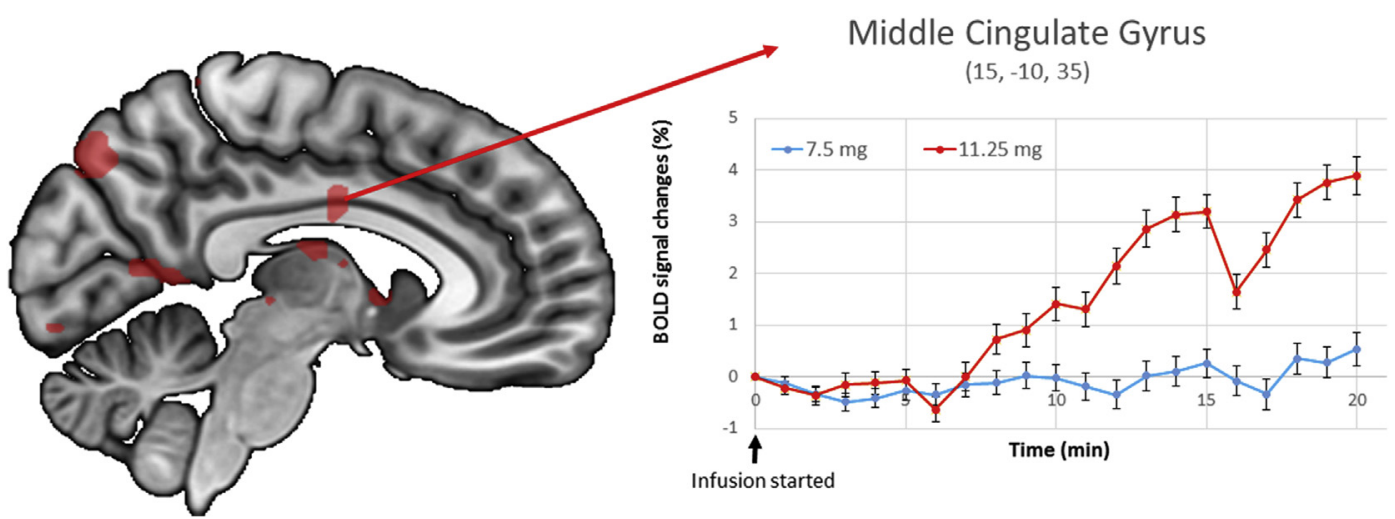

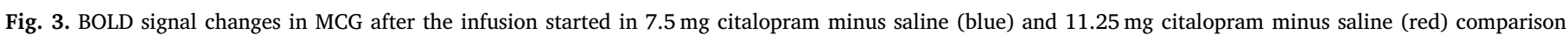
showing dose-dependent activation changes over time with error bars indicating standard error (SE).

the significantly activated brain areas to achieve the 'optimal set' of relationships between investigated variables. Notable relationships between personality traits and brain areas detected with LASSO regression included self-consciousness-MCG $\quad(R B=0.37)$, anxiety-thalamus $(\mathrm{RB}=0.30)$ and anxiety-midbrain $(\mathrm{RB}=0.10)$. Fig. 4 shows an adaptive graphical lasso based model with the mean values of adaptive graphical LASSO coefficients, computed using 100 generated models. For detailed results of LASSO analysis and relevant relationship between activation changes of brain areas see Supplementary Table 5.

\section{Discussion}

Our direct pharmacological challenge study of acute citalopram as a probe of serotonergic neurotransmission revealed widespread and significant activation in several brain areas that are part of the default mode network (posterior cingulate gyrus, precuneus, angular gyrus, MTG and parahippocampal gyrus), the visual network (lingual gyrus, cuneus, fusiform gyrus and middle occipital gyrus), and the sensorimotor network (postcentral gyrus). Thus, we successfully applied and also extended to female participants the previously reported (McKie et al., 2005) citalopram phMRI method to follow direct regional BOLD response to serotonergic stimulation while also investigating the effect of a higher dose. Using a stricter significance threshold $\left(\mathrm{p}_{\mathrm{FWE}}<0.05\right)$ compared to the original study ( $\mathrm{p}<0.001$ ) in a larger sample we found a similar pattern of activation. However, some of these activations including well-known regions with dense serotonergic innervation, such as the amygdala, and clusters involving the thalamus and midbrain, showed significant activation only at a higher dose. The most significant dose effect of citalopram was detected in the MCG, a key hub of reflexive orientation toward sensory stimuli (Vogt, 2014). In addition, time-series analysis revealed that the activation pattern travelled in an occipito-frontal direction suggesting that acute serotonin reuptake inhibition initially facilitates visual information processing with downstream involvement of subcortical motor, frontal executive regions and threat evaluation in amygdala (Supplementary video).

We also demonstrated that the total BOLD response to citalopram is associated with neuroticism, a trait-like endophenotype for several neuropsychiatric disorders and a potent modulator of emotional arousal and threat processing (Goldstein and Klein, 2014; Kehoe et al., 2012). By modelling the subscales of neuroticism together with activated brain areas we demonstrated LASSO-relevant relationships between anxiety and thalamus, anxiety and midbrain, and self-consciousness and the MCG. These results further support serotonergic neurotransmission having an important role in determining neuroticism and therefore vulnerability to depression, anxiety and pain disorders.

\subsection{Brain activation pattern during acute citalopram challenge}

PET studies reported low 5HTT levels in most cortical areas except the limbic lobe and a diverse distribution of different 5-HT receptor types across the whole brain (Saulin et al., 2012; Savli et al., 2012). In addition, a previous PET/MR study investigating the pharmacological response to citalopram showed that intravenous administration of $8 \mathrm{mg}$ citalopram over $8 \mathrm{~min}$ led to $69 \pm 7 \%$ 5HTT occupancy after the challenge (Gryglewski et al., 2019). Althougth the dose and timeframe

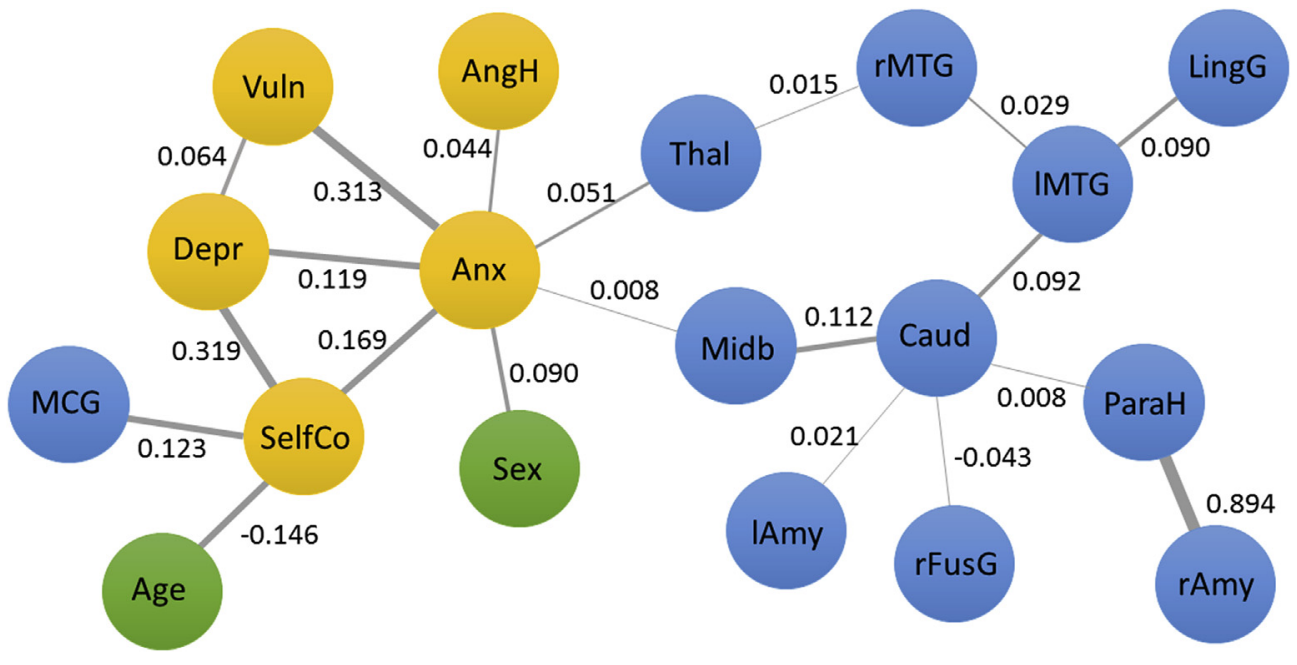

Fig. 4. Adaptive graphical lasso based model with the mean values of adaptive graphical LASSO coefficients, computed using 100 generated models. The thickness of lines represents the strength of relationships between variables. Colors: blue - peak regions, yellow - neuroticism facets from NEO-P-R, green - other covariates (sex and age). SelfCo - self-consciousness, Depr depression, Vuln - vulnerability, Anx - anxiety, AngH - angry hostility, MCG - middle cingulate gyrus, Thal - thalamus, rMTG right middle temporal gyrus, IMTG - left middle temporal gyrus, LingG - lingual gyrus, Midb - midbrain, Caud - caudate, ParaH - parahippocampal gyrus, rFusG right fusiform gyrus, lAmy - left amygdala, rAmy - right amygdala. 
of the citalopram infusion is almost the same as in our study, no citalopram-evoked BOLD responses were observed in the PET/MR study. The authors suggested that scanner drift might have matched their occupancy regressors thus obscuring BOLD changes. Correction for drift in the present study may therefore account for the significant changes in BOLD signal due to citalopram challenge we observed.

Much is known about the distribution of 5HTT and 5-HT receptors in the human brain that would be engaged by 5-HT release following citalopram challenge (Savli et al., 2012). The most accepted hypothesis regarding the effect of SSRIs is that increased synaptic serotonin levels activate high affinity 5-HT1A inhibitory heteroreceptors on GABA-ergic inhibitory interneurons and consequentially disinhibit glutamatergic pyramidal cell activity which is the driver of neurovascular coupling and the BOLD response (Chilmonczyk et al., 2015; Klaassens et al., 2015). It is likely that other 5-HT receptors and neurotransmitters in serotonergic projection areas take part in the observed activation changes, especially at higher doses. However, in this study we cannot draw a conclusion on the exact mechanisms behind the observed BOLD signal changes due the diversity of 5-HT receptor and 5HTT distribution in different brain regions and the complex relationships of 5-HT with other neurotransmitter systems. Nevertheless, the net cortical disinhibition could be the origin of extensive decreases in functional brain connectivity in resting state networks observed after single oral doses of SSRIs in several studies (Klaassens et al., 2015, 2017, 2018; Schwarz et al., 2009; Schaefer et al., 2014).

\subsection{Dose effect of acute citalopram challenge}

Microdialysis studies demonstrated that the extracellular increase of serotonin elicited by blockade of 5HTT using SSRIs is dose dependent (Bel and Artigas, 1992). In addition, a previous phMRI study showed widespread and dose-dependent BOLD activation changes to acute citalopram treatment in rats (Sekar et al., 2011). In our study, we found similar widespread brain activation following the higher citalopram dose that additionally activated brain areas with dense serotonergic innervation including the midbrain, caudate, and thalamus. Activation of similar functional networks has been described in rat phMRI studies following acute i.v. fluoxetine (Schwarz et al., 2007, 2009) where responses correlated with raphe nuclei activation in the same subcortical structures as in our study, such as thalamus, caudate and amygdala (Schwarz et al., 2007). The extended activation might be related to the quantitative effect of a more potent 5HTT blockade and increased synaptic serotonin content resulting from the higher dose but we could not exclude that receptors with less affinity for serotonin, such as the excitatory 5-HT2A receptor, contribute to this effect (Chilmonczyk et al., 2015; Marek et al., 2003).

The MCG showed a clear significant dose-dependent increase in BOLD signal surviving whole-brain correction. The MCG is a key central site controlling rapid motoric body orientation response during sensory information processing and is primarily involved in Go/approach behaviour instead of noGo/avoidance response; a process which occurs before emotional/cognitive assessments of other brain areas (Vogt, 2014). Our study provides evidence of dose-dependent modulation of MCG activation by serotonergic innervation in the human brain, which may contribute to the mechanism of antidepressant action and represent a potential biomarker for depression and recovery in the light of previous evidence that this region is involved in the pathomechanism of unipolar depression and stress-related disorders (Vogt, 2014).

\subsection{Acutely increased serotonergic neurotransmission and heightened arousal}

Our group-level analysis indicate that acutely increasing synaptic serotonin enhances BOLD signal in several brain regions with none showing whole-brain significant decreases in BOLD signal during the citalopram challenge. The observed pattern of activation shows similarity with brain activation related to emotional arousal during threat processing. For example, Farrow and colleagues (Farrow et al., 2012) demonstrated that skin conductance changes during exposure to threatening vs harmless stimuli were significantly associated with brain activation in the lingual gyrus, precuneus, MCG, postcentral gyrus, bilateral precentral gyrus/supplementary motor area, medial prefrontal cortex and thalamus. Increased arousal increases emotion processing and involves extensive brain areas related to promotion of survival, such as facilitation of sensory information processing of environmental triggers, focus of attention to internal and external stimuli, and motoric orientation towards the source of information (LeDoux, 2012). We speculate that acute citalopram-induced increases in synaptic serotonin content produces a brain state similar to increased arousal, despite the fact that no significant pulse rate, blood pressure or arousal symptom changes were seen at the doses we applied. There is increasing interest in dysregulation of arousal as a transdiagnostic process (Hegerl and Hensch, 2014; Huang et al., 2015; Sander et al., 2015) contributing not only to the pathogenesis of depression (Hegerl et al., 2012) but also to other psychiatric disorders including anxiety (Domschke et al., 2010) and chronic pain disorders (Foo and Mason, 2003); indeed arousal has become a transdiagnostic research domain in the Research Domain Criteria project (RDoc) (Cuthbert, 2014; Morris and Cuthbert, 2012). Furthermore, increased arousal in depression (Hegerl et al., 2012; Schmidt et al., 2016, 2017) may be an important determinant of antidepressant treatment outcome, with studies showing that a subgroup of responders have heightened and faster reduction of arousal during antidepressant treatment compared to non-responders (Olbrich et al., 2016; Schmidt et al., 2017). Our findings suggest there could be a serotonergic basis to transdiagnostic dysfunctional arousal in psychiatric disorders. This could be a fruitful area of further investigation.

\subsection{Brain serotonin neurotransmission and neuroticism}

Several studies investigated neuroimaging biomarkers of personality traits such as neuroticism, an important endophenotype of depression, anxiety and chronic pain (Wade et al., 1992; Weinstock and Whisman, 2006). Association between neuroticism and decreased 5HT1A receptor binding in several brain regions with the strongest negative correlation in the hippocampus, superior temporal gyrus and prefrontal cortex (Hirvonen et al., 2015), and increased 5-HT2A receptor binding in frontolimbic regions has been reported in previous PET studies (Frokjaer et al., 2008).

Our study demonstrated an association between neuroticism and BOLD activation during the lower citalopram dose $(7.5 \mathrm{mg})$ in the thalamus and midbrain with correlation between the anxiety component of neuroticism and BOLD activation changes in the thalamus and midbrain. This is in line with a previous neuroimaging study that showed a positive correlation between neuroticism and 5-HTT binding in the thalamus (Takano et al., 2007), but a similar study found no such association (Kalbitzer et al., 2009) while another showed an association between 5-HTT binding and neuroticism but with opposite directions in males and females (Tuominen et al., 2017). The positive association of anxiety with increased functional serotonergic function is compatible with the increased anxiety that commonly occurs early in SSRI therapy which is probably mediated by excessive 5-HT2C function with toleration occurring after repeated treatment (Deakin, 2013; Deakin and Graeff, 1991).

The region that showed a significant dose effect in the MCG in our study also showed a correlation with the self-consciousness facet of neuroticism. A previous study reported decreased functional coupling between the MCG and amygdala during emotion suppression associated with self-consciousness (Chen et al., 2017). Several studies have found that the function of an area corresponding to the MCG may be related to neuroticism (DeYoung et al., 2010; Kano et al., 2014), but interpretation is hindered by the lack of standard nomenclature, since it is sometimes labelled as anterior or posterior cingulate cortex (Kumari 
et al., 2007; Tzschoppe et al., 2014).

Altogether, our results, consistent with previous neuroimaging studies, provide evidence of a relationship between neuroticism and function of the thalamus, midbrain, and MCG, and indicate that this relationship is mediated by the functional state of serotonin neurotransmission. This may also shed further light on the therapeutic effect of SSRIs, as previous studies have shown that neuroticism may have a role in the effect of SSRI treatment outcome in depressed patients beyond improved mood (Quilty et al., 2008; Tang et al., 2009). We speculate that SSRIs could bring about positive neuroplastic changes in neural circuits related to neuroticism that might be necessary to stabilise remission in neuropsychiatric disorders where neuroticism is an important risk factor.

\section{Limitations}

Our study has some limitations. We included only healthy participants and the findings need to be related to changes in patients with depression, anxiety and chronic pain disorders. In addition, the sample size for the dose-response is small and administration was not blinded for the $11.25 \mathrm{mg}$ citalopram challenge. Nevertheless, we found highly significant activation changes with 9 participants in the $11.25 \mathrm{mg}$ minus saline comparison occurring in regions with well-known serotonergic innervation, consistent with previous research. We did not measure physiological or performance measures of arousal and clearly the possible relationship to regional brain effects of citalopram challenge is speculative. However, the brain regions that responded with increased BOLD signal were similar to brain activation related to emotional arousal during threat processing. Nevertheless, our inferences need direct tests in future studies designed specifically to measure brain activation changes to external stressors and its relations to citalopram challenge.

\section{Conclusion}

Acute i.v. citalopram administration not only elicited dose dependent increasing brain activation in several regions involved in serotonergic neurotransmission and part of the default mode, visual and sensorimotor networks, but individual response differences were associated with neuroticism. Activated brain regions were similar to those involved in arousal and as neuroticism entails a tendency for heightened stress reactivity, our results could reflect modulating effect of serotonin to process environmental stressors, which may also play a role in therapeutic effects of SSRIs.

\section{Declaration of competing interest}

AEE is an employee of Gedeon Richter Plc. Medical Division, but the company did not provide any funding, or had any further role in the preparation of the article. JFWD variously performed consultancy, speaking engagements and research for P1vital, Autifony and AstraZeneca; fees are paid to the University of Manchester; he has share options in P1vital. IMA has received consultancy fees from Servier, Alkermes, Lundbeck/Otsuka and Janssen, an honorarium for speaking from Lundbeck and grant support from Servier and AstraZeneca. All other authors report no financial relationships with commercial interests.

\section{Acknowledgement}

The study was supported by the MTA-SE-NAP B Genetic Brain Imaging Migraine Research Group, Hungarian Academy of Sciences, Semmelweis University (Grant No. KTIA_NAP_13-2-2015-0001); Hungarian Brain Research Program (Grant No. 2017-1.2.1- NKP-201700002); by the National Institute for Health Research Manchester Biomedical Research Centre; the Hungarian Academy of Sciences
(MTA-SE Neuropsychopharmacology and Neurochemistry Research Group); by ITM/NKFIH Thematic Excellence Programme, Semmelweis University; by the SE-Neurology FIKP grant of EMMI; and by the BMEBiotechnology FIKP grant of EMMI (BME FIKP-BIO). XG and LRK was supported by the Bolyai Research Fellowship Program of the Hungarian Academy of Sciences. ES was supported by ÚNKP-17-3-III-ELTE-346 and GH was supported by ÚNKP-17-4-BME-115 and XG was supported by ÚNKP-18-4-SE-33 and AEE was supported by ÚNKP-18-3-III-SE-6 New National Excellence Program of the Ministry of Human Capacities. The sponsors had no further role in the study design; in the collection, analysis and interpretation of data; in the writing of the report; and in the decision to submit the paper for publication. The authors thank Mate Magyar, Eva Csepany, Adam Gyorgy Szabo, Natalia Kocsel, Attila Galambos, Krisztina Olah Koosne, Istvan Kobor, and Mark Folyovich for their contribution.

\section{Appendix A. Supplementary data}

Supplementary data to this article can be found online at https:// doi.org/10.1016/j.neuropharm.2019.107807.

\section{References}

Anderson, I.M., Del-Ben, C.M., McKie, S., Richardson, P., Williams, S.R., Elliott, R., Deakin, J.F.W., 2007. Citalopram modulation of neuronal responses to aversive face emotions: a functional MRI study. Neuroreport 18, 1351-1355.

Anderson, I.M., Juhasz, G., Thomas, E., Downey, D., McKie, S., Deakin, J.F., Elliott, R., 2011. The effect of acute citalopram on face emotion processing in remitted depression: a pharmacoMRI study. Eur. Neuropsychopharmacol. 21, 140-148.

Anderson, I.M., McKie, S., Elliott, R., Williams, S.R., Deakin, J.F., 2008. Assessing human 5-HT function in vivo with pharmacoMRI. Neuropharmacology 55, 1029-1037.

Attenburrow, M.J., Mitter, P.R., Whale, R., Terao, T., Cowen, P.J., 2001. Low-dose citalopram as a 5-HT neuroendocrine probe. Psychopharmacology 155, 323-326.

Bel, N., Artigas, F., 1992. Fluvoxamine preferentially increases extracellular 5-hydroxytryptamine in the raphe nuclei: an in vivo microdialysis study. Eur. J. Pharmacol. 229, 101-103.

Belsky, J., Jonassaint, C., Pluess, M., Stanton, M., Brummett, B., Williams, R., 2009. Vulnerability genes or plasticity genes? Mol. Psychiatry 14, 746-754.

Booij, L., Tremblay, R.E., Szyf, M., Benkelfat, C., 2015. Genetic and early environmental influences on the serotonin system: consequences for brain development and risk for psychopathology. J. Psychiatry Neurosci. 40, 5-18.

Browning, M., Reid, C., Cowen, P.J., Goodwin, G.M., Harmer, C.J., 2007. A single dose of citalopram increases fear recognition in healthy subjects. J. Psychopharmacol. 21, 684-690.

Castren, E., 2005. Is mood chemistry? Nat. Rev. Neurosci. 6, 241-246.

Castren, E., 2013. Neuronal network plasticity and recovery from depression. JAMA Psychiatry 70, 983-989.

Chen, S., Chen, C., Yang, J., Yuan, J., 2017. Trait self-consciousness predicts amygdala activation and its functional brain connectivity during emotional suppression: an fMRI analysis. Sci. Rep. 7, 117.

Chilmonczyk, Z., Bojarski, A., Pilc, A., Sylte, I., 2015. Functional selectivity and antidepressant activity of serotonin 1A receptor ligands. Int. J. Mol. Sci. 16, 18474.

Costa, P.T., McCrae, R.R., 1992. Revised NEO Personality Inventory (NEO PI-R) and NEO Five-Factor Inventory (NEO-FFI). Psychological Assessment Resources.

Cuthbert, B.N., 2014. The RDoC framework: facilitating transition from ICD/DSM to dimensional approaches that integrate neuroscience and psychopathology. World Psychiatry 13, 28-35.

Deakin, J., 2013. The origins of '5-HT and mechanisms of defence' by Deakin and Graeff: a personal perspective. J. Psychopharmacol. 27, 1084-1089.

Deakin, J.F., Graeff, F.G., 1991. 5-HT and mechanisms of defence. J. Psychopharmacol. 5, 305-315.

Del-Ben, C.M., Deakin, J.F., McKie, S., Delvai, N.A., Williams, S.R., Elliott, R., Dolan, M., Anderson, I.M., 2005. The effect of citalopram pretreatment on neuronal responses to neuropsychological tasks in normal volunteers: an FMRI study. Neuropsychopharmacology 30, 1724-1734.

DeYoung, C.G., Hirsh, J.B., Shane, M.S., Papademetris, X., Rajeevan, N., Gray, J.R., 2010 Testing predictions from personality neuroscience. Brain structure and the big five. Psychol. Sci. 21, 820-828.

Domschke, K., Stevens, S., Pfleiderer, B., Gerlach, A.L., 2010. Interoceptive sensitivity in anxiety and anxiety disorders: an overview and integration of neurobiological findings. Clin. Psychol. Rev. 30, 1-11.

Downey, D., Dutta, A., McKie, S., Dawson, G.R., Dourish, C.T., Craig, K., Smith, M.A. McCarthy, D.J., Harmer, C.J., Goodwin, G.M., Williams, S., Deakin, J.F., 2016. Comparing the actions of lanicemine and ketamine in depression: key role of the anterior cingulate. Eur. Neuropsychopharmacol. 26, 994-1003.

Epskamp, S., Borsboom, D., Fried, E.I., 2017. Estimating psychological networks and their accuracy: a tutorial paper. Behav. Res. Methods 50, 195-212.

Farrow, T.F., Johnson, N.K., Hunter, M.D., Barker, A.T., Wilkinson, I.D., Woodruff, P.W., 2012. Neural correlates of the behavioral-autonomic interaction response to 
potentially threatening stimuli. Front. Hum. Neurosci. 6, 349

Foo, H., Mason, P., 2003. Brainstem modulation of pain during sleep and waking. Sleep Med. Rev. 7, 145-154.

Fox, E., Zougkou, K., Ridgewell, A., Garner, K., 2011. The serotonin transporter gene alters sensitivity to attention bias modification: evidence for a plasticity gene. Biol Psychiatry 70, 1049-1054.

Frokjaer, V.G., Mortensen, E.L., Nielsen, F.A., Haugbol, S., Pinborg, L.H., Adams, K.H., Svarer, C., Hasselbalch, S.G., Holm, S., Paulson, O.B., Knudsen, G.M., 2008. Frontolimbic serotonin 2A receptor binding in healthy subjects is associated with personality risk factors for affective disorder. Biol. Psychiatry 63, 569-576.

Gaspar, P., Cases, O., Maroteaux, L., 2003. The developmental role of serotonin: news from mouse molecular genetics. Nat. Rev. Neurosci. 4, 1002-1012.

Godlewska, B.R., Browning, M., Norbury, R., Cowen, P.J., Harmer, C.J., 2016. Early changes in emotional processing as a marker of clinical response to SSRI treatment in depression. Transl. Psychiatry 6 (11), e957.

Godlewska, B.R., Norbury, R., Selvaraj, S., Cowen, P.J., Harmer, C.J., 2012. Short-term SSRI treatment normalises amygdala hyperactivity in depressed patients. Psychol. Med. 42, 2609-2617.

Goldstein, B.L., Klein, D.N., 2014. A review of selected candidate endophenotypes for depression. Clin. Psychol. Rev. 34, 417-427.

Gryglewski, G., Klöbl, M., Berroterán-Infante, N., Rischka, L., Balber, T., Vanicek, T., Pichler, V., Kautzky, A., Klebermass, E.M., Reed, M.B., Vraka, C., Hienert, M., James, G.M., Silberbauer, L., Godbersen, G.M., Unterholzner, J., Michenthaler, P. Hartenbach, M., Winkler-Pjrek, E., Wadsak, W., Mitterhauser, M., Hahn, A., Hacker, M., Kasper, S., Lanzenberger, R., 2019. Modeling the acute pharmacological response to selective serotonin reuptake inhibitors in human brain using simultaneous PET/ MR imaging. Eur. Neuropsychopharmacol. 29 (6), 711-719.

Hariri, A.R., Holmes, A., 2006. Genetics of emotional regulation: the role of the serotonin transporter in neural function. Trends Cogn. Sci. 10, 182-191.

Harmer, C.J., Bhagwagar, Z., Perrett, D.I., Vollm, B.A., Cowen, P.J., Goodwin, G.M., 2003. Acute SSRI administration affects the processing of social cues in healthy volunteers. Neuropsychopharmacology 28, 148-152.

Harmer, C.J., Cowen, P.J., 2013. 'It's the way that you look at it'-a cognitive neuropsychological account of SSRI action in depression. Philos. Trans. R. Soc. Lond. B Biol. Sci. 368, 20120407.

Harmer, C.J., Mackay, C.E., Reid, C.B., Cowen, P.J., Goodwin, G.M., 2006. Antidepressant drug treatment modifies the neural processing of nonconscious threat cues. Biol. Psychiatry 59, 816-820.

Hegerl, U., Hensch, T., 2014. The vigilance regulation model of affective disorders and ADHD. Neurosci. Biobehav. Rev. 44, 45-57.

Hegerl, U., Wilk, K., Olbrich, S., Schoenknecht, P., Sander, C., 2012. Hyperstable regulation of vigilance in patients with major depressive disorder. World. J. Biol. Psychiatry. 13, 436-446.

Hirvonen, J., Tuominen, L., Nagren, K., Hietala, J., 2015. Neuroticism and serotonin 5 HT1A receptors in healthy subjects. Psychiatry Res. 234, 1-6.

Huang, J., Sander, C., Jawinski, P., Ulke, C., Spada, J., Hegerl, U., Hensch, T., 2015. Testretest reliability of brain arousal regulation as assessed with VIGALL 2.0. Neuropsychiatr. Electrophysiol 1, 13

Kalbitzer, J., Frokjaer, V.G., Erritzoe, D., Svarer, C., Cumming, P., Nielsen, F.A., Hashemi, S.H., Baare, W.F., Madsen, J., Hasselbalch, S.G., Kringelbach, M.L., Mortensen, E.L., Knudsen, G.M., 2009. The personality trait openness is related to cerebral 5-HTT levels. Neuroimage 45, 280-285.

Kano, M., Coen, S.J., Farmer, A.D., Aziz, Q., Williams, S.C., Alsop, D.C., Fukudo, S., O'Gorman, R.L., 2014. Physiological and psychological individual differences influence resting brain function measured by ASL perfusion. Brain Struct. Funct. 219, 1673-1684.

Kehoe, E.G., Toomey, J.M., Balsters, J.H., Bokde, A.L., 2012. Personality modulates the effects of emotional arousal and valence on brain activation. Soc. Cogn. Affect. Neurosci. 7, 858-870.

Khalili-Mahani, N., Rombouts, S.A., van Osch, M.J., Duff, E.P., Carbonell, F., Nickerson, L.D., Becerra, L., Dahan, A., Evans, A.C., Soucy, J.P., Wise, R., Zijdenbos, A.P., van Gerven, J.M., 2017. Biomarkers, designs, and interpretations of resting-state fMRI in translational pharmacological research: a review of state-of-the-Art, challenges, and opportunities for studying brain chemistry. Hum. Brain Mapp. 38, 2276-2325.

Klaassens, B.L., Rombouts, S.A., Winkler, A.M., van Gorsel, H.C., van der Grond, J., van Gerven, J.M., 2017. Time related effects on functional brain connectivity after serotonergic and cholinergic neuromodulation. Hum. Brain Mapp. 38, 308-325.

Klaassens, B.L., van Gerven, J.M.A., Klaassen, E.S., van der Grond, J., Rombouts, S., 2018. Serotonergic and cholinergic modulation of functional brain connectivity: a comparison between young and older adults. Neuroimage 169, 312-322.

Klaassens, B.L., van Gorsel, H.C., Khalili-Mahani, N., van der Grond, J., Wyman, B.T., Whitcher, B., Rombouts, S.A.R.B., van Gervend, J.A., 2015. Single-dose serotonergic stimulation shows widespread effects on functional brain connectivity. Neuroimage 122, 440-450.

Klomp, A., van Wingen, G.A., de Ruiter, M.B., Caan, M.W.A., Denys, D., Reneman, L., 2013. Test-retest reliability of task-related pharmacological MRI with a single-dose oral citalopram challenge. Neuroimage 75, 108-116.

Kraus, C., Castrén, E., Kasper, S., Lanzenberger, R., 2017. Serotonin and neuroplasticity links between molecular, functional and structural pathophysiology in depression. Neurosci. Biobehav. Rev. 77, 317-326.

Kumari, V., ffytche, D.H., Das, M., Wilson, G.D., Goswami, S., Sharma, T., 2007. Neuroticism and brain responses to anticipatory fear. Behav. Neurosci. 121, 643-652. LeDoux, J., 2012. Rethinking the emotional brain. Neuron 73, 653-676.

Lesch, K.P., Bengel, D., Heils, A., Sabol, S.Z., Greenberg, B.D., Petri, S., Benjamin, J., Muller, C.R., Hamer, D.H., Murphy, D.L., 1996. Association of anxiety-related traits with a polymorphism in the serotonin transporter gene regulatory region. Science
274, 1527-1531

Lotrich, F.E., Bies, R., Muldoon, M.F., Manuck, S.B., Smith, G.S., Pollock, B.G., 2005. Neuroendocrine response to intravenous citalopram in healthy control subjects: pharmacokinetic influences. Psychopharmacology 178, 268-275.

Macoveanu, J., 2014. Serotonergic modulation of reward and punishment: evidence from pharmacological fMRI studies. Brain Res. 1556, 19-27.

Marek, G.J., Carpenter, L.L., McDougle, C.J., Price, L.H., 2003. Synergistic action of 5 HT2A antagonists and selective serotonin reuptake inhibitors in neuropsychiatric disorders. Neuropsychopharmacology 28, 402-412.

McKie, S., Del-Ben, C., Elliott, R., Williams, S., del Vai, N., Anderson, I., Deakin, J.F., 2005. Neuronal effects of acute citalopram detected by pharmacoMRI. Psychopharmacology (Berl) 180, 680-686.

Middeldorp, C.M., de Geus, E.J., Beem, A.L., Lakenberg, N., Hottenga, J.J., Slagboom, P.E., Boomsma, D.I., 2007. Family based association analyses between the serotonin transporter gene polymorphism (5-HTTLPR) and neuroticism, anxiety and depression. Behav. Genet. 37, 294-301.

Morris, S.E., Cuthbert, B.N., 2012. Research Domain Criteria: cognitive systems, neural circuits, and dimensions of behavior. Dialogues Clin. Neurosci. 14, 29-37.

McFarquhar, M., 2019. Modeling group-level repeated measurements of neuroimaging data using the univariate general linear model. Front. Neurosci. 13, 352.

Munafo, M.R., Freimer, N.B., Ng, W., Ophoff, R., Veijola, J., Miettunen, J., Jarvelin, M.R., Taanila, A., Flint, J., 2009. 5-HTTLPR genotype and anxiety-related personality traits: a meta-analysis and new data. Am. J. Med. Genet. B Neuropsychiatr. Genet. 150B, 271-281.

Murphy, S.E., Norbury, R., O'Sullivan, U., Cowen, P.J., Harmer, C.J., 2009. Effect of a single dose of citalopram on amygdala response to emotional faces. Br. J. Psychiatry 194, 535-540.

Olbrich, S., Trankner, A., Surova, G., Gevirtz, R., Gordon, E., Hegerl, U., Arns, M., 2016. CNS- and ANS-arousal predict response to antidepressant medication: findings from the randomized iSPOT-D study. J. Psychiatr. Res. 73, 108-115.

Pringle, A., Harmer, C.J., 2015. The effects of drugs on human models of emotional processing: an account of antidepressant drug treatment. Dialogues Clin. Neurosci. 17, 477-487.

Quilty, L.C., Meusel, L.A., Bagby, R.M., 2008. Neuroticism as a mediator of treatment response to SSRIs in major depressive disorder. J. Affect. Disord. 111, 67-73.

Sander, C., Hensch, T., Wittekind, D.A., Bottger, D., Hegerl, U., 2015. Assessment of wakefulness and brain arousal regulation in psychiatric research. Neuropsychobiology 72, 195-205.

Saulin, A., Savli, M., Lanzenberger, R., 2012. Serotonin and molecular neuroimaging in humans using PET. Amino Acids 42, 2039-2057.

Savli, M., Bauer, A., Mitterhauser, M., Ding, Y.S., Hahn, A., Kroll, T., Neumeister, A., Haeusler, D., Ungersboeck, J., Henry, S., Isfahani, S.A., Rattay, F., Wadsak, W., Kasper, S., Lanzenberger, R., 2012. Normative database of the serotonergic system in healthy subjects using multi-tracer PET. Neuroimage 63, 447-459.

Schaefer, A., Burmann, I., Regenthal, R., Arélin, K., Barth, C., Pampel, A., Villringer, A. Margulies, D.S., Sacher, J., 2014. Serotonergic modulation of intrinsic functional connectivity. Curr. Biol. 24, 2314-2318.

Schmidt, F.M., Pschiebl, A., Sander, C., Kirkby, K.C., Thormann, J., Minkwitz, J., Chittka T., Weschenfelder, J., Holdt, L.M., Teupser, D., Hegerl, U., Himmerich, H., 2016. Impact of serum cytokine levels on EEG-measured arousal regulation in patients with major depressive disorder and healthy controls. Neuropsychobiology 73, 1-9.

Schmidt, F.M., Sander, C., Dietz, M.E., Nowak, C., Schroder, T., Mergl, R., Schonknecht, P., Himmerich, H., Hegerl, U., 2017. Brain arousal regulation as response predictor for antidepressant therapy in major depression. Sci. Rep. 7, 45187.

Schwarz, A.J., Gozzi, A., Bifone, A., 2009. Community structure in networks of functional connectivity: resolving functional organization in the rat brain with pharmacological MRI. Neuroimage 47, 302-311.

Schwarz, A.J., Gozzi, A., Reese, T., Bifone, A., 2007. In vivo mapping of functional connectivity in neurotransmitter systems using pharmacological MRI. Neuroimage 34, 1627-1636.

Sekar, S., Verhoye, M., Van Audekerke, J., Vanhoutte, G., Lowe, A.S., Blamire, A.M., Steckler, T., Van der Linden, A., Shoaib, M., 2011. Neuroadaptive responses to citalopram in rats using pharmacological magnetic resonance imaging. Psychopharmacology (Berl) 213, 521-531.

Smith, D.J., Escott-Price, V., Davies, G., Bailey, M.E., Colodro-Conde, L., Ward, J. Vedernikov, A., Marioni, R., Cullen, B., Lyall, D., Hagenaars, S.P., Liewald, D.C., Luciano, M., Gale, C.R., Ritchie, S.J., Hayward, C., Nicholl, B., Bulik-Sullivan, B., Adams, M., Couvy-Duchesne, B., Graham, N., Mackay, D., Evans, J., Smith, B.H., Porteous, D.J., Medland, S.E., Martin, N.G., Holmans, P., McIntosh, A.M., Pell, J.P., Deary, I.J., O'Donovan, M.C., 2016. Genome-wide analysis of over 106000 individuals identifies 9 neuroticism-associated loci. Mol. Psychiatry 21, 1644.

Symonds, C.S., McKie, S., Elliott, R., Deakin, W.J.F., Anderson, I.M., 2012. Detection of the acute effects of hydrocortisone in the hippocampus using pharmacological fMRI. Eur. Neuropsychopharmacol. 22, 867-874.

Takano, A., Arakawa, R., Hayashi, M., Takahashi, H., Ito, H., Suhara, T., 2007. Relationship between neuroticism personality trait and serotonin transporter binding. Biol. Psychiatry 62, 588-592.

Tang, T.Z., DeRubeis, R.J., Hollon, S.D., Amsterdam, J., Shelton, R., Schalet, B., 2009. Personality change during depression treatment: a saline-controlled trial. Arch. Gen. Psychiatr. 66, 1322-1330.

Terracciano, A., Balaci, L., Thayer, J., Scally, M., Kokinos, S., Ferrucci, L., Tanaka, T., Zonderman, A.B., Sanna, S., Olla, N., Zuncheddu, M.A., Naitza, S., Busonero, F., Uda, M., Schlessinger, D., Abecasis, G.R., Costa Jr., P.T., 2009. Variants of the serotonin transporter gene and NEO-PI-R Neuroticism: No association in the BLSA and SardiNIA samples. Am. J. Med. Genet. B Neuropsychiatr. Genet. 150B, 1070-1077.

Tuominen, L., Miettunen, J., Cannon, D.M., Drevets, W.C., Frokjaer, V.G., Hirvonen, J., 
Ichise, M., Jensen, P.S., Keltikangas-Jarvinen, L., Klaver, J.M., Knudsen, G.M., Takano, A., Suhara, T., Hietala, J., 2017. Neuroticism associates with cerebral in vivo serotonin transporter binding differently in males and females. Int. J. Neuropsychopharmacol. 20, 963-970.

Tzourio-Mazoyer, N., Landeau, B., Papathanassiou, D., Crivello, F., Etard, O., Delcroix, N., Mazoyer, B., Joliot, M., 2002. Automated anatomical labeling of activations in SPM using a macroscopic anatomical parcellation of the MNI MRI single-subject brain. Neuroimage 15, 273-289.

Tzschoppe, J., Nees, F., Banaschewski, T., Barker, G.J., Buchel, C., Conrod, P.J., Garavan, H., Heinz, A., Loth, E., Mann, K., Martinot, J.L., Smolka, M.N., Gallinat, J., Strohle, A., Struve, M., Rietschel, M., Schumann, G., Flor, H., consortium, I., 2014. Aversive learning in adolescents: modulation by amygdala-prefrontal and amygdala-hippocampal connectivity and neuroticism. Neuropsychopharmacology 39, 875-884.

Umemori, J., Winkel, F., Didio, G., Llach Pou, M., Castrén, E., 2018. iPlasticity: induced juvenile-like plasticity in the adult brain as a mechanism of antidepressants. Psychiatry Clin. Neurosci. 72, 633-653.

Vogt, B.A., 2014. Submodalities of emotion in the context of cingulate subregions. Cortex 59, 197-202.

Wade, J.B., Dougherty, L.M., Hart, R.P., Rafii, A., Price, D.D., 1992. A canonical correlation analysis of the influence of neuroticism and extraversion on chronic pain, suffering, and pain behavior. Pain 51, 67-73.

Weinstock, L.M., Whisman, M.A., 2006. Neuroticism as a common feature of the depressive and anxiety disorders: a test of the revised integrative hierarchical model in a national sample. J. Abnorm. Psychol. 115, 68-74.

Willis-Owen, S.A., Turri, M.G., Munafo, M.R., Surtees, P.G., Wainwright, N.W., Brixey, R.D., Flint, J., 2005. The serotonin transporter length polymorphism, neuroticism, and depression: a comprehensive assessment of association. Biol. Psychiatry 58, $451-456$. 